Jurnal Dinamika Sosial Ekonomi Vol.20 No.1, Juni 2019 : 14-25

ISSN 1411-593X (print)

\title{
PENERAPAN PRINSIP KEMITRAAN PADA U.D. PANTIBOGA NATURAL FOOD SPECIALIST DENGAN RAHMA JAYA HERBAL DI KECAMATAN MATESIH KABUPATEN KARANGANYAR
}

\author{
Application of Partnership Principles of U.D Pantiboga Natural Food \\ Specialist With Rahma Jaya Herbal in Matesih District, Karanganyar Regency
}

\author{
Rochmat Musthofa*, Daru Retnowati, Vandrias Dewantoro \\ Program Studi Agribisnis, Fakultas Pertanian, Universitas Pembangunan Nasional \\ "Veteran" Yogyakarta \\ Jl. SWK 104, Kecamatan Depok, Kabupaten Sleman,Yogyakarta, Indonesia \\ email korespondensi: rohmad.musthofa@yahoo.com
}

Diterima tanggal : 13 Januari 2019 ; Disetujui tanggal : 10 April 2019

\begin{abstract}
The purposes of this study to describe the partnership pattern that is applied in the process of product marketing of UD Pantiboga and Rahma Jaya Herbal Home Industry and then review the application of the partnership principles in the partnership program. The method used in this research was qualitative method. The technique of determining informants which is the owner of UD Pantiboga and the owner of Rahma Jaya Herbal Home Industry was purposive. Data sources were primary data and secondary data. However, the data collection techniques was observation, interviews, documentation by testing validity of the data use triangulation. Data analysis techniques were collecting data, reducing data, drawing conclusions, and product marketing processes was included in the general trading partnership pattern. The pattern of general trade partnership of both UD Pantiboga and Rahma Jaya Herbal Home Industry was a business partnership because it has implemented the principles of partnership but not yet maximally caused by the responsibility regarding product packaging security and the absence of written agreements based on law in establishing partnerships that have the potential for later violations day.
\end{abstract}

Keywords: Marketing Process, Partnership Pattern, Partnership Principles

\begin{abstract}
ABSTRAK
Penelitian ini bertujuan untuk mendiskripsikan pola kemitraan yang diterapkan dalam hal proses pemasaran produk antara UD Pantiboga dengan Home Industry Rahma Jaya Herbal dan kemudian mengkaji penerapan prinsip kemitraan dalam program kemitraan tersebut. Metode yang digunakan dalam penelitian ini adalah metode kualitatif. Teknik penentuan informan yaitu purposive dengan informannya adalah pemilik UD Pantiboga dan Pemilik Home Industry Rahma Jaya Herbal. Sumber data yang digunakan adalah data primer dan sekunder, sedangkan teknik pengumpulan data yaitu observasi, wawancara, dokumentasi dengan pengujian keabsahan data menggunakan triangulasi. Teknis
\end{abstract}


analisis data yaitu mengumpulkan data, mereduksi data, penarikan kesimpulan, dan penyajian data. Hasil penelitian menunjukkan bahwa pola kemitraan yang diterapkan oleh UD Pantiboga dengan Home Industry Rahma Jaya Herbal dalam kerjasama proses pemasaran produk adalah termasuk ke dalam pola kemitraan dagang umum. Pola kemitraan dagang umum antara UD Pantiboga dengan Home Industry Rahma Jaya Herbal merupakan kemitraan usaha karena sudah menerapkan prinsip-prinsip kemitraan akan tetapi belum maksimal disebabkan oleh tanggung jawab mengenai keamanan kemasan produk dan tidak adanya kesepakatan tertulis berlandaskan hukum dalam menjalin kemitraan yang berpotensi terjadinya pelanggaran dikemudian hari.

Kata Kunci: Proses Pemasaran, Pola Kemitraan, Prinsip Kemitraan

\section{PENDAHULUAN}

Obat herbal telah diterima secara luas di negara berkembang dan di negara maju. Menurut WHO, hingga $65 \%$ dari penduduk negara maju dan $80 \%$ penduduk negara berkembang telah menggunakan obat herbal. Faktor pendorong terjadinya peningkatan penggunaan obat herbal di negara maju adalah : i) meningkatnya usia harapan hidup pada saat prevalensi penyakit kronik meningkat, ii) adanya kegagalan penggunaan obat modern untuk penyakit tertentu seperti kanker, serta iii) semakin meluasnya akses informasi obat herbal di seluruh dunia (Hidayat, 2014).

Menurut Fauzan (2015), kemitraan usaha adalah kerjasama usaha antara usaha kecil (termasuk petani dan nelayan) dengan usaha menengah atau dengan usaha besar dengan memperhatikan prinsip saling memerlukan, memperkuat dan saling menguntungkan. Program Kemitraan Agribisnis telah tumbuh sejak tahun 1970-an Menurut Fauzan (2015), perkembangan program ini mencapai puncaknya dengan diterbitkannya kebijakan kemitraan dalam bentuk Peraturan Pemerintah (PP) No. 47/1997 tentang Kemitraan, yang mengatur pola kerja sama dengan prinsip kemitraan untuk UMKM. Kebijakan program kemitraan merupakan salah satu strategi pembangunan andalan pemerintah yang berpihak kepada pengusaha kecil dan menengah. Kebijakan ini berisi aturan main jaminan hak serta kewajiban perusahaan inti dan plasma, pola hubungan sinergi antara perusahaan inti dan plasma, serta mendudukkan peranan pemerintah sebagai pembina dan fasilitator sekaligus pendukung dana program kemitraan. 
Kemitraan akan mempengaruhi kinerja usaha. Bejawi dan Hamilton (2012) juga menyatakan bahwa pelaksanaan kemitraan usaha berpengaruh positif dan signifikan terhadap kinerja usaha finansial dan non-finansial. Salah satu contoh kemitraan yang terdapat di Karanganyar adalah kemitraan antara UD Pantiboga yang memproduksi Red Rice Bran dan Home Industry Rahma Jaya Herbal yang memproduksi temulawak. Pemasaran Red Rice Bran yang telah tersebar di sekitar daerah Karanganyar dilakukan melalui sistem agen-agen, sedangkan untuk menjangkau daerah yang jauh dapat memesan dengan cara online. Melihat pemasaran Red Rice Bran dari UD Pantiboga yang telah luas maka Home industry Rahma Jaya Herbal di daerah Giribangun, Kecamatan Matesih, Kabupaten Karanganyar bekerjasama dalam hal proses pemasaran produk. Selain itu Rahma Jaya Herbal juga bekerjasama dengan DISPERINDAGKOP, Dinas Pariwisata dan Dinas Pertanian yang mempromosikan produk temulawaknya melalui acara pameran-pameran produk. Selama memproduksi temulawak, Home industry Rahma jaya Herbal belum pernah mengalami kerugian karena prospek pemasaran minuman herbal ini cukuplah bagus.

UD Pantiboga memasarkan produk Temulawak milik Home Industry Rahma Jaya Herbal. Sebaliknya Industri Rumah Tangga Rahma Jaya Herbal juga memasarkan produk Red Rice Bran milik UD Pantiboga. Namun terkadang ada kendala yang harus dihadapi oleh UD Pantiboga dan Home Industry Rahma Jaya Herbal yang berpotensi dan dapat mengganggu keberlangsungan proses kemitraan dalam pemasaran produk, diantaranya yaitu berkurangnya persediaan bahan baku dan menjadikan tingginya harga bahan baku yang diakibatkan dari pemasaran produk pertanian yang kurang lancar menjadikan kegairahan para petani menurun sehingga menyebabkan berkurangnya produk yang dibuat oleh industri demikian juga proses pemasaran menjadi jarang dilakukan lagi atau tidak terjadwal dengan jelas. Kesepakatan dalam program kerjasama UD Pantiboga dengan Home Industry Rahma Jaya Herbal tidak dibuat MoU ataupun kesepakatan tertulis yang berlandaskan hukum yang kuat akan tetapi kedua belah pihak hanya menyatakan kesepakatan secara lisan dan menyebut program 
kerjasama dalam proses pemasaran produk tersebut adalah kemitraan usaha.

UD Pantiboga dan Home Industry Rahma Jaya Herbal melakukan kerjasama dalam proses pemasaran produk dengan berlandaskan kekeluargaan. Tidak adanya kesepakatan yang berlandaskan hukum yang kuat dalam kemitraan usaha akan berpotensi terjadi pelanggaran di kemudian hari. Good Corporate Governance (GCG) adalah suatu istilah yang sudah tidak asing lagi. Di Indonesia istilah ini sudah menjadi bahan diskusi yang serius, sejak terjadi krisis ekonomi tahun 1997. Krisis yang terjadi di Indonesia ini menurut para praktisi pakar ekonomi disebabkan oleh belum adanya atau lemahnya pelaksanaan Good Corporate Governance (GCG) di perusahaan-perusahaan. Pelanggaran prinsip-prinsip GCG bisa terjadi karena lemahnya peraturan perundang-undangan di Indonesia, minimnya peraturan akan batasan antara hak dan kewajiban pihak yang terkait dengan kinerja perusahaan, sertater cermin dari kurang tersedianya informasi untuk melakukan analisis, adanya investasi berlebihan, kurang atau menurunnya produktivitas perusahaan. Sebagian dari kalangan bisnis menafsirkan GCG hanya sebatas bagaimana perusahaan agar dapat meningkatkan laba yang besar dalam pemasaran.

Selain prinsip GCG ada prinsip kemitraan yang harus dipenuhi oleh pihak yang bermitra, 5 prinsip dalam kemitraan antara lain adalah Equality (Kesetaraan), Transparency (Transparansi), Result-oriented approach (Pendekatan berorientasi hasil), Responsibility (tanggung jawab), dan Complementarity (Pelengkap) (Kaihatu, 2006). Adapun penelitian ini bertujuan 1) mengkaji pola kemitraan UD Pantiboga dengan Home Industry Rahma Jaya Herbal di Kecamatan Matesih, Kabupaten Karanganyar. 2) mengkaji penerapan prinsip-prinsip kemitraan dalam hal proses pemasaran produk antara UD Pantiboga dan Home Industry Rahma Jaya Herbal.

\section{METODE PENELITIAN}

\section{Lokasi dan Waktu Penelitian}

Penelitian ini berlokasi di UD Pantiboga yang terletak diDesa Plosorejo, RT.002/RW.002, Kecamatan Matesih, Kabupaten Karanganyar dan Home 
Industry Rahma Jaya Herbal yang terletak di Dusun Karang Bangun, Kecamatan Matesih, Kabupaten Karanganyar. Pelaksanaan penelitian akan dilaksanakan dalam kurun waktu April 2018 sampai dengan Mei 2018.

\section{Subyek Penelitian}

Subyek penelitian adalah individu, benda, atau organisme yang dijadikan sumber informasi yang dibutuhkan dalam pengumpulan data. Dalam penelitian kualitatif subyek penelitian disebut dengan informan, yaitu orang yang memberi informasi tentang data yang diinginkan peneliti berkaitan dengan penelitian yang dilaksanakannya. Pada penelitian ini yang menjadi subyek penelitian adalah UD Pantiboga dan Home Industry Rahma Jaya Herbal yang saling bekerjasama dalam kemitaraan proses pemasaran produk.

\section{Jenis Penelitian}

Jenis penelitian ini menggunakan metode kualitatif yaitu suatu metode dalam meneliti status sekelompok manusia, suatu objek, suatu kondisi, suatu sistem pemikiran atau suatu kelas peristiwa pada masa sekarang. Tujuan dari penelitian deskriptif ini adalah untuk membuat deskripsi, gambaran atau lukisan secara sistematis, faktual dan akurat mengenai fakta-fakta serta hubungan antar fenomena yang diselidiki.

Dalam penelitian kualitatif peneliti memasuki situasi sosial tertentu, peneliti melakukan observasi dan wawancara kepada orang-orang yang dipandang tahu tentang situasi sosial tersebut. Penentuan informan dilakukan menggunakan purposive sampling, yaitu peneliti memilih informan tertentu dengan pertimbangan akan memberikan data yang diperlukan dengan lengkap.

Ada enam langkah dalam proses menganalisis data kualitatif yaitu :

a. Mempersiapkan dan mengorganisasikan data untuk analisis

Pengelolaan data pada penelitian kualitatif awal terdiri atas mengorganisasikan data, mentranskripsikan wawancara dan mengetikkan catatan lapangan, dan mengambil keputusan untuk menganalisis datanya dengan tangan atau komputer. 
b. Mengeksplorasi dan Mengode Data

Peneliti kualitatif melaksanakan analisis pendahuluan terhadap data dengan membacanya secara seksama untuk mendapatkan perasaan umum tentang data. Proses pengodean adalah mereduksi basis-data teks atau gambar menjadi deskripsi atau tema tentang orang, tempat atau kejadian. Hal ini melibatkan memeriksa basis-data teks kalimat demi kalimat, menanyakan pada diri sendiri tentang apa yang dikatakan oleh partisipan, dan kemudian memberikan label kode pada segmen teks tersebut.

c. Mengode untuk membangun deskripsi dan tema

Kode kemudian digunakan untuk mengembangkan deskripsi tentang orang dan tempat. Mereka juga digunakan untuk mengembangkan tema yang menyuguhkan abstraksi yang lebih luas daripada kode. Tema ini dapat berlapis-lapis atau diorganisasikan untuk menceritakan suatu kisah atau dapat saling dihubungkan satu sama lain untuk memotret kompleksitas fenomena.

d. Merepresentasikan dan melaporkan temuan kualitatif

Peneliti kualitatif merepresentasikan temuan mereka dalam tampilan visual yang mungkin termasuk gambar, diagram, tabel perbandingan, dan tabel demografis. Mereka melaporkan temuan dalam diskusi naratif yang terdiri atas banyak bentuk, seperti kronologi, pertanyaan, atau komentar tentang perubahan yang dialami para partisipan.

e. Menginterpretasikan temuan

Menginterpretasikan temuan kegiatannya yaitu dari melaporkan dan menginterpretasikan temuan, peneliti kualitatif membuat interpretasi tentang makna penelitian. Interpretasi ini terdiri atas mengemukakan pandangan pribadi, membuat perbandingan antara temuan dan kepustakaan, dan menyebutkan keterbatasan serta menyarankan penelitian dimasa mendatang.

f. Memvalidasi Keakuratan Temuan

Untuk memeriksa keakuratan penelitiannya, peneliti kualitatif sering menerapakan prosedur validasi, seperti member checking, triangulasi, dan auditing. Maksud validasi adalah untuk meminta partisipan, peninjau 
eksternal, atau sumber data itu sendiri untuk memberikan bukti tentang keakuratan informasi dalam laporan kualitatif (Creswell, 2015). Penelitian ini menggunakan metode kualitatif karena masalah penelitian belum jelas. Strategi yang digunakan dalam penelitian ini adalah studi kasus. Studi kasus adalah suatu studi tentang kekhasan dan sekaligus kompleksitas dari suatu atau sejumlah kasus, guna memahami kegiatan subyek peneliti dalam kondisi tertetu,dengan menerapkan sejumlah metode pengumpulan data yang saling melengkapi.

\section{HASIL DAN PEMBAHASAN}

\section{Analisis Pola Kemitraan UD Pantiboga dengan Home Industry Rahma Jaya Herbal.}

1. Bentuk kerjasama proses pemasaran produk antara UD Pantiboga dengan Home Industry Rahma Jaya Herbal

Kemitraan adalah jalinan kerjasama antara berbagai pelaku agribisnis, mulai dari tingkat produksi sampai tingkat pemasaran (Supriyati dan Roosganda, 2009). Keuntungan yang didapatkan ketika terbentuk kemitraan adalah adanya kepastian pemasaran, hasil dan keuntungan relative lebih stabil, memeroleh kemudahaan akses permodalan dan resiko kerugian lebih rendah (Rudiyanto, 2014).

a. Kepahaman tentang kemitraan usaha

Kemitraan adalah suatu jalinan kerjasama saling menguntungkan antara pihak yang bermitra usaha demi tercapainya kelancaran jalannya usaha dan memperluas pemasaran. Menurut Purba (2008), kerjasama yang terbentuk harus berlandaskan kepercayaan dan komitmen antara partner. Selaras dengan hal tersebut.

b. Alasan menjalin kemitraan usaha

Alasan UD Pantiboga bermitra dengan Home Industry Rahma Jaya Herbal adalah untuk menjalin hubungan kekerabatan antar anggota UMKM karanganyar, memperluas pemasaran produk, dan mengembangkan produk jamu agar bermanfaat bagi banyak orang. 
c. Syarat dalam menjalankan kemitraan usaha Syarat menjalankan kerjasama proses pemasaran produk yang harus ditempuh dalam bermitra antara UD Pantiboga dengan home industry Rahma Jaya Herbal adalah harus saling menguntungkan, harus saling mempromosikan dan menjualkan produk, dan produk yang sudah dibeli tidak boleh dikembalikan jika melewati masa kadaluwarsa. Syarat- syarat tersebut ditetapkan berdasarkan keputusan bersama antara UD Pantiboga dan home industry Rahma Jaya Herbal.

d. Pembagian hasil dari program kemitraan pemasaran produk

Hasil yang diperoleh UD Pantiboga dan Home Industry Rahma Jaya Herbal adalah dari keuntungan didapatkan dengan menaikkan harga dari harga beli produk grosir. Harga normal Rice Red Bran adalah Rp. 10.000 per bungkus tetapi UD Pantiboga memberi harga grosir yakni Rp. 5000 per bungkus kemasan sachet Rice Red Bran jika ingin menjadi mitra ataupun agen UD Pantiboga. UD Pantiboga juga menjual Temulawak yang dibeli dari Home Industry Rahma Jaya Herbal seharga Rp. 12.000. Harga normal Temulawak adalah Rp. 18.000 per botol.

2. Saluran pemasaran produk Temulawak dan dan Rice Red Bran oleh Home Industry Rahma Jaya Herbal

Saluran pemasaran produk Temulawak dan Rice Red Bran antara lain di Kemuning Resto Karnganyar yang rutin memesan 300 botol Temulawak dan 200 Rice rice bran sebulan) tetapi kebanyakan pembayaran dilakukan di belakang (kongsinyasi), Rumah Makan Mbak Ning yang rutin memesan 100 botol Temulawak dan 50 Rice rice bran sebulan) tetapi kebanyakan pembayaran dilakukan di belakang (kongsinyasi), Toko Gethuk Semar Wonogiri produk Temulawak sebanyak 120 botol dan 80 bungkus Red Rice Bran sebulan, pembeli lewat online di instagram atau WhatsApp di berbagai daerah, pembeli mendatangi rumah produksi Rahma Jaya Herbal langsung membeli produk ke outlet kecil yang dibangun di samping rumah.

3. Saluran pemasaran produk Temulawak dan Rice Red Bran oleh UD Pantiboga 
Saluran pemasaran Temulawak dan Rice Red Bran oleh UD Pantiboga antara lain di daerah Solo yaitu di Toko Mbah Sinco pengiriman 2 minggu sekali dengan jumlah rata-rata $50 \mathrm{Kg}$ Red Rice Bran dan $50 \mathrm{Kg}$ Temulawak, daerah Semarang yaitu di (Toko Herbal Pak Wawan, Pak Arbon, dan Pak Wiwit) pengiriman rutin satu bulan sekali rata-rata $40 \mathrm{Kg}$ Bekatul dan 40 Kg Temulawak di masing-masing toko herbal, dan penjualan online lewat instagram.

\section{Analisis Penerapan Prinsip Kemitraan dalam Hal Proses Pemasaran Produk}

\section{Antara UD Pantiboga dan Home industry Rahma Jaya Herbal.}

\section{a. Penerapan prinsip Equality (Kesetaraan)}

Salah satu konsep dasar kemitraan adalah penjalinan kerjasama antara dua pihak atau lebih dalam kegiatan usaha dimana pihak yang bermitra mempunyai kedudukan yang "sejajar" (equal standing) (Azhari, 2000). Salah satu bukti adanya kesetaraan adalah dengan adanya kesepakatan yang terjalin antara dua pihak. Kualitas produk ditetapkan berdasarkan kesepakatan UD Pantiboga dan Home Industry Rahma Jaya Herbal yaitu bersertifikat P-IRT, mengunakan bahan baku berkualitas, produk harus dikemas dengan baik dan harus mencantumkan batas kadaluwarsa.

\section{b. Penerapan prinsip Transparency (Keterbukaan)}

Transparansi diperlukan untuk menghindari rasa saling curiga antar mitra kerja. Meliputi transparansi pengelolaan informasi dan transparansi pengelolaan keuangan (Wulandari dan Murwani, 2018). Pengambilan keputusan dilakukan oleh UD Pantiboga dan Home industry Rahma Jaya Herbal ketika akan menaikkan harga produk, proses pengiriman produk, dan ketika kordinasi mengenai pembagian tugas disaat diundang untuk menghadiri pameran produk UMKM. Keputusan bersama antara UD Pantiboga dan Home Industry Rahma Jaya Herbal dilaksanakan dan saling melaporkan hasilnnya. Pelaporan pengambilan jumlah produk dan pengembalian sisa produk Rice Red Bran/Temulawak yang dipasarakan dengan menggunakan nota bon jika dilakukan 
pembayaran dibelakang. Pelaporan kegiatan proses pemasaran produk dilakukan ketika ada permintaan oleh konsumen dan stok habis maka melapor ke pihak mitra untuk segera dikirimkan produknya.

c. Penerapan prinsip Result-oriented approach (Pendekatan Berorientasi Hasil)

Penerapan prinsip Result-oriented approach (Pendekatan Berorientasi Hasil) mengacu pada dampak yang dirasakan oleh UD Pantiboga dan Home Industry Rahma Jaya Herbal selama bermitra.Dampak oleh UD Pantiboga selama menjalankan program kemitraan dengan Home Industry Rahma Jaya Herbal adalah pemasaran produk menjadi luas, penjualan produk meningkat, dan omset bertambah.

d. Penerapan prinsip Responsibility (Tanggung Jawab)

Penerapan prinsip Responsibility (Tanggung Jawab) dalam program kerjasama proses pemasaran produk antara UD Pantiboga dan Home Industry Rahma Jaya Herbal ditinjau dari tindakan dalam menjaga kinerja untuk mengemban tugas dan tanggung jawab ketika bermitra usaha. Dalam bermitra UD Pantiboga dan Home Industry Rahma Jaya Herbal melakukan tugas dan peran dengan sungguh-sungguh dan menjunjung prinsip kekeluargaan, tidak hanya berbisnis tetapi juga saling menjalin silaturahmi antar mitra usaha. Tugas dan tanggung jawab UD Pantiboga dan Home Industry Rahma Jaya Herbal sebagai mitra adalah membantu mempromosikan dan memasarkan produk, menjaga produk harus tetap dalam kondisi baik disaat pengiriman ke pelanggan. Tugas proses pemasaran produk dilakukan dengan komunikasi melalui HP (handphone) dengan melaporkan kondisi persediaan barang yang dijual.

e. Penerapan prinsip Complementarity (Saling Melengkapi)

Penerapan prinsip Complementarity (Saling Melengkapi) dalam kerjasama proses pemasaran produk antara UD Pantiboga dengan Home Industry 
Rahma Jaya Herbal dapat diidentifikasi melalui kapasitas kelembagaan dan kapasitas manajerial. UD Pantiboga dan Home Industry Rahma Jaya Herbal ikut serta menjadi anggota himpunan UMKM Kabupaten Karanganyar dengan berpartisipasi pada setiap kegiatan yang diprogramkan oleh PemKab Karanganyar demi memperluas relasi dan pemasaran. Semua kegiatan dari himpunan UMKM Karanganyar untuk mengembangkan usaha anggota UMKM. Kegiatan dalam himpunan UMKM Kabupaten Karanganyar adalah pelatihan, pameran, kunjungan studi banding, dan seminar kewirausahaan.

\section{KESIMPULAN DAN SARAN}

\section{Kesimpulan}

Kesimpulan yang dapat diambil adalah pola kemitraan yang diterapkan oleh UD Pantiboga dengan Home Industry Rahma Jaya Herbal dalam kerjasama proses pemasaran produk termasuk ke dalam pola kemitraan dagang umum. Pola kemitraan dagang umum antara UD Pantiboga dengan Home Industry Rahma Jaya Herbal merupakan kemitraan usaha karena sudah menerapkan prinsipprinsip kemitraan akan tetapi belum maksimal.

\section{Saran}

Saran yang dapat diberikan adalah bagi UD Pantiboga dan Home Industry Rahma Jaya Herbal agar membuat surat kesepakatan tertulis (MoU) yang berisi tentang aturan kemitraan yang berlaku untuk UD Pantiboga dan Home Industry Rahma Jaya Herbal, hal ini dimaksudkan agar dalam bermitra lebih aman dan dinaungi oleh hukum yang berlaku sehingga mengurangi potensi terjadinya pelanggaran dikemudian hari.

Bagi Home Industry Rahma Jaya Herbal untuk menghindari return produk yang hampir kadaluwarsa dari outlet-outlet yang dititipi produk maka sebaiknya membuat jadwal untuk penarikan produk herbal yang belum laku dari outlet-outlet yang jarang pengunjung untuk diambil dan dialihkan ke outlet-outlet yang ramai pengunjung hal ini dimaksudkan agar produk cepat terjual. 
Bagi Home Industry Rahma Jaya Herbal untuk menjaga dari hal yang tidak diinginkan oleh pihak lain agar memperbaiki label kadaluwarsa yang semula dari tulisan kertas yang direkatkan dengan solasi sebaiknya diganti dengan cap yang permanen agar aman dan tidak mudah diganti.

\section{DAFTAR PUSTAKA}

Azhari, Azril. (2000). Kemitraan Agribisnis Tiga Tungku. Jurnal Ekonomi dan Bisnis Indonesia, 15 (2) : 186-200.

Bejawi, T dan R. D. Hamilton. (2012). The Effect of External Social Resources On Firm Patent Performance : The Impact of Boards, Partnership, and Geographic Proximity. Journal of Business and Entrepreneurship, Fall 2012: $43-62$.

Creswell. (2015). Riset Pendidikan. Yogyakarta: Pustaka Pelajar.

Fauzan. (2015). Pola Kemitraan Agribisnis. Gorontalo: Ideas Publishing.

Hidayat. (2014). Bisnis Memasarkan Produk Herbal. Diakses dari http://www.bisnishack.com/2014/09/7-cara-memasarkan-bisnis-produkherbal.html.

Kaihatu, T.S. (2006). Good Corporate Governance dan Penerapannya di Indonesia. Jurnal Ekonomi Manajemen, 8(1), 1-9. Doi: http://jmk.petra.ac.id/repository/transfer/MAN06080101.pdf

Purba, E.A. (2008). Analisis Penerapan Strategi Kemitraan terhadap Kinerja Perusahaan Biro Teknik Listrik (Studi Empiris pada Hubungan PT. PLN (Persero) Distribusi Jateng-DIY Area Pelayanan dan Jaringan Semarang dengan Perusahaan Biro Teknik Listrik (BTL) di Wilayah Kerja APJ Semarang). Jurnal Bisnis Strategi, 17 (2), 197-202.

Rudiyanto, A.A. (2014). Pola Kemitraan Koperasi Sejahtera Abadi dalam Meningkatkan Keuntungan Petani Cabai. JEJAK : Journal of Economics $\begin{array}{lllll}\text { and } \quad \text { Policy, } & \text { (2), } & \text { 100-202. }\end{array}$ http://dx.doi.org/10.15294/jejak.v7i1.3596

Supriyati., dan Roosganda E. (2009). Pensejahteraan Petani dan Pengembangan Agribisnismelalui Pengembangan Kelembagaan Kemitraan dalam Pemasaran Cabai Merah. Seminar Nasional Peningkatan Daya Saing Agribisnis Berorientasi Kesejahteraan Petani. Bogor.

Wulandari, S., Murwani, S.I. (2018). Pola Kemitraan dalam Pengembangan Pariwisata di Kabupaten Purbalingga Provinsi Jawa Tengah. Jurnal Manajemen Pembangunan, 5(2), 171-190. 